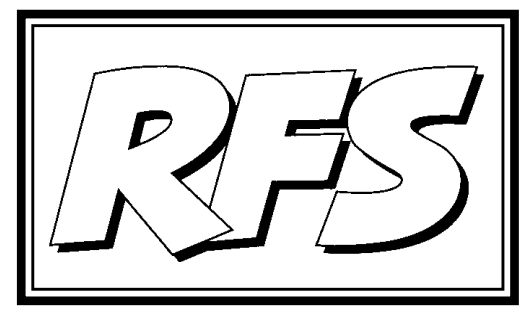

Revista de Fomento Social, 61 (2006), 185-212

\title{
La Ayuda Oficial al Desarrollo bilateral española en educación en el período 1999-2004: perfil y recomendaciones
}

Ma Luz ORTEGA CARPIO, Ana HERNÁNDEZ ROMÁN, Mercedes TORRES JIMÉNEZ ${ }^{1}$

(Palabras clave: EduCación, Desarrollo humano, Ayuda Oficial al Desarkollo, COOPERACIÓN BILATERAL, CODIFICACIÓN CRS

KEy WORDS: EDUCATION, HuMAN DEVELOPMENT, OfFICIAL DeVELOPMENT AID,

BILATERAL COOPERATION, CRS CODIFICATION)

1 Profesoras de laFacultad de CC. Económicas y Empresariales-ETEA, adscrita a la Universidad de Córdoba. 


\section{Introducción}

Apesar de que existe una concienciación generalizada de que laEducación es una pieza clave para el desarrollo de los pueblos, y la cooperación española así loconsidera, puesto que el sector educativo es uno de los principales receptores defondos de la Ayuda Oficial al Desarrollo (AOD) bilateral ${ }^{2}$ española, no existía, sin embargo, hasta la fecha ningún análisis temporal sobre la ayuda española en esta materia, tan sólo estudios parciales relativos a años concretos y con reducido soporte cuantitativo. La ausencia de datos veraces, fundamentalmente relativos a la cooperación descentralizada ${ }^{3}$, y la correspondiente dificultad en el tratamiento de los mismos, explica este vacío en los estudios realizados hasta el momento. Precisamente, en este trabajo se analiza qué ha hecho la cooperación bilateral española durante los últimos años para contribuir a la mejora de la educación de los países en desarrollo. En concreto, analizaremos la importancia cuantitativa de la AOD bilateral destinada al sector educativo, su distribución geográfica y sectorial, quiénes han financiado la ayuda, qué papel tienen las ONGD en este contexto, qué instrumentos se han utilizado, etc. Una vez dibujado el perfil de la AOD bilateral española en educación pasaremos a establecer las principales conclusiones extraídas del análisis y propondremos una serie de recomendaciones que creemos necesarias para la mejora de la calidad y la eficacia de la ayuda.

\section{Metodología}

Se ha realizado un análisis estadístico descriptivo de la AOD bilateral española destinada a educación durante los años 1999 a 2004. Los datos que se han tomado como base para esta investigación proceden de los listados de proyectos de la AOD bilateral registrados anualmente por la Dirección Gene-

2 La AOD bilateral está constituida por los flujos de fondos directos entre países donantes y receptores, mientras que la multilateral la componen los fondos canalizados a través de organismos internacionales de desarrollo.

3 La cooperación descentralizada es la que realizan las administraciones autonómicas y locales; por el contrario, la cooperación centralizada es la que realiza la administración central.

4 El presente estudio forma parte de una investigación más amplia que se ha llevado a cabo en virtud de un acuerdo de colaboración entre ETEA (Institución Universitaria de la Compañía de Jesús) y las ONGD Entreculturas y Alboan. Fruto de esta colaboración, en diciembre de 2005 se publicó el informe que lleva por título La AOD en Educación a examen. Un análisis de la cooperación española: 1999-2004. Se puede acceder al informe completo en la siguiente dirección: http://www.fundacionetea.org/docs/aodCompleto.pdf. 
ral de Planificación y Evaluación de Políticas para el Desarrollo (DGPOLDE), dependiente de la Secretaría de Estado de Cooperación Internacional (SECI), la cual a su vez depende del Ministerio de Asuntos Exteriores y Cooperación. Dichos listados se encuentran disponibles en línea ${ }^{5}$ y constituyen la fuente sobre la que se elaboran anualmente los Seguimientos de los Planes Anuales de Cooperación Internacional (PACI).

Para realizar el análisis se unificaron los listados de proyectos anuales de estos seis años en una única base de datos, y se seleccionaron aquellos casos pertenecientes al sector educación, quedando un total de 4.633 proyectos, que constituyen los casos objeto de este estudio ${ }^{6}$.

En dicha base de datos los proyectos están clasificados según el sector de destino en el país receptor de la ayuda, siguiendo el sistema de clasificación Creditor Reporting System, más conocido como códigos CRS del Comité de Ayuda al Desarrollo (CAD) ${ }^{7}$. El código CRS es un número de 5 cifras que sirve para identificar, dentro de cada sector del código CAD, los distintos "subsectores" que lo constituyen. En concreto, dentro del sector CAD de Educación (código 100), se incluyen los siguientes subsectores ${ }^{8}$ :

- Educación, nivel no especificado (código CAD 111), que incluye los códigos CRS: Política educativa y gestión administrativa, Servicios e instalaciones educativos y formación y Formación de profesores $e$ investigación educativa. Los códigos de esta categoría se deben aplicar únicamente cuando se desconozca o no se especifique el nivel educativo correspondiente para un determinado proyecto.

5 Estos listados de proyectos, que anteriormente se encontraban en la página web de la AECI, se pueden descargar, desde principios de 2006, en la siguiente dirección de Internet: http:// www.maec.es/es/MenuPpal/Cooperacion+Internacional/La+AOD+española.+Estadísticas/.

Hemos de advertir que en el momento en que se hizo este estudio aún no estaban disponibles los datos relativos a las contribuciones bilaterales del año 2004, los cuales han sido publicados a finales de abril de 2006. Los datos que en el estudio se han manejado para dicho año son los que figuraban en un listado provisional que nos fue facilitado por la DGPOLDE en septiembre de 2005 .

6 En el anexo aparece recogida una definición exhaustiva de las variables objeto de estudio.

7 Se puede acceder al documento que explica detalladamente la clasificación con codificación CAD y CRS en la dirección http://www.oecd.org/dataoecd/25/31/6863909.pdf

8 Para que el lector pueda distinguir en el texto la mención a las etapas educativas establecidas por el sistema CAD de las del sistema CRS, las primeras figurarán con su nombre resaltado en negrita y las segundas en cursiva. 
- Educación básica (código CAD 112), que incluye Educación primera infancia, Educación primaria y Capacitación básica de jóvenes y adultos.

- Educación secundaria (código CAD 113), que incluye Educación secundaria propiamente dicha y Formación profesional.

- Educación postsecundaria (código CAD 114), que incluye Educación universitaria y Formación superior técnica y de dirección.

\section{El perfil de la AOD bilateral española en educación}

Hemos analizado la importancia cuantitativa de la AOD bilateral española en educación, su distribución geográfica y sectorial, los principales agentes implicados en su concesión y ejecución, así como los instrumentos más utilizados, extrayendo las conclusiones que se indican a continuación.

1. En el período 1999-2004 la AOD bilateral bruta ${ }^{9}$ española ascendió a algo más de 6.710 millones de euros (más de 1,12 billones de pesetas), de los cuales 783 millones, es decir, el 11,7\% se destinaron al sector educativo. En la tabla 1 se puede observar la evolución que han seguido en el período 1999-2004 la AOD destinada al sector educación y la AOD bruta bilateral total.

Según se desprende de los datos recogidos en la tabla 1 en el año 2000 los fondos destinados a Educación se multiplicaron por más de dos; en los años 2001 y 2002 se mantuvieron aproximadamente en el mismo nivel; pero en los dos últimos años del período la cuantía destinada al sector educativo disminuyó considerablemente, reduciéndose, con relación al año anterior, en 21 millones de euros en 2003 y en 38 millones en 2004. Se observa también que la evolución que ha seguido en este mismo período la AOD bilateral total ha sido muy diferente a la que ha seguido la AOD destinada a educación.

9 La ayuda bilateral puede ser de carácter reembolsable (créditos que el país receptor deberá devolver) o de carácter no reembolsable (donaciones). La AOD bilateral bruta está constituida por los flujos de fondos brutos, es decir, sin descontar las devoluciones que se han producido en el período. Si a la AOD bruta se le restan las devoluciones se obtiene la denominada AOD neta. 
TABLA 1

Evolución de la AOD bilateral bruta española y de la AOD en educación en el período 1999-2004 (cifras absolutas en millones de euros)

\begin{tabular}{|l|r|r|c|c|c|c|}
\hline \multicolumn{1}{|c|}{ CONCEPTO } & $\mathbf{1 9 9 9}$ & $\mathbf{2 0 0 0}$ & $\mathbf{2 0 0 1}$ & $\mathbf{2 0 0 2}$ & $\mathbf{2 0 0 3}$ & $\mathbf{2 0 0 4}$ \\
\hline AOD bilateral bruta & 778,5 & 887,2 & $1.377,60$ & $1.222,40$ & $1.198,61$ & $1.246,30$ \\
\hline AOD educación & 74,2 & 156,4 & 155,4 & 159,1 & 138,2 & 100,1 \\
\hline $\begin{array}{l}\text { \% AOD educación/AOD } \\
\text { bilat. bruta }\end{array}$ & 9,5 & 17,6 & 11,3 & 13 & 11,5 & 8 \\
\hline $\begin{array}{l}\text { Variación interanual } \\
\text { AOD-bilat. bruta (\%) }\end{array}$ & & 14,0 & 55,3 & $-11,3$ & $-1,9$ & 4,0 \\
\hline $\begin{array}{l}\text { Variación interanual } \\
\text { AOD-educ. (\%) }\end{array}$ & & 110,8 & $-0,6$ & 2,4 & $-13,1$ & $-27,6$ \\
\hline
\end{tabular}

FUENTE: Listado de proyectos 1999 a 2003 y listado provisional de proyectos 2004, DGPOLDE. Elaboración propia.

2. Respecto a su importancia relativa, el sector educativo es un sector prioritario dentro de la cooperación española. Del análisis de la distribución entre sectores $\mathrm{CAD}$ se desprende que la cuantía de fondos que la cooperación bilateral española ha destinado al sector educación en el período 1999-2004 sólo es superada por la destinada a las actividades relacionadas con la deuda (890 millones de euros). No obstante, si consideramos solamente las contribuciones distribuibles por sectores ${ }^{10}$, que suponen aproximadamente $2 / 3$ de la AOD bilateral bruta total en este período (algo más de 4.496 millones de euros) la educación pasa a ser el sector que más fondos concentra tal y como podemos observar en el gráfico 1 .

10 Las contribuciones no distribuibles por sectores se componen fundamentalmente de las operaciones de deuda, la acción humanitaria, los programas de seguridad alimentaria, los costes administrativos y todas aquellas acciones cuyo sector no está especificado. 


\section{GRÁFICO 1 \\ Distribución sectorial de la AOD bilateral española durante 1999-2004 (contribuciones distribuibles)}

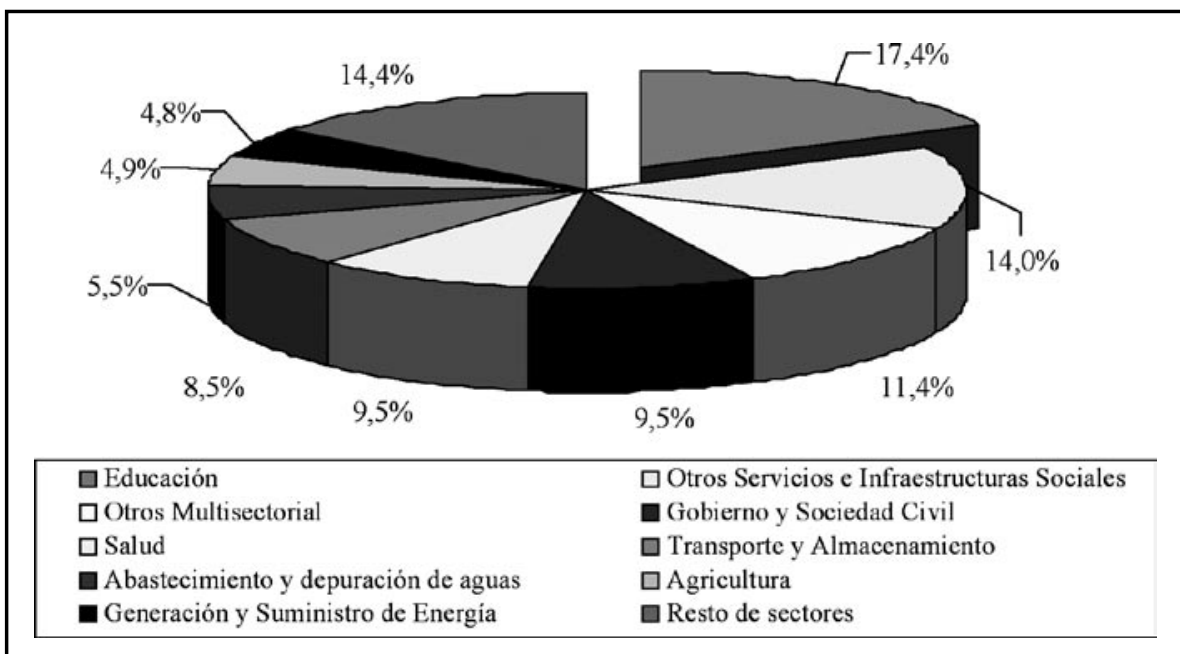

FUENTE: Listado de proyectos 1999 a 2003 y listado provisional de proyectos 2004, DGPOLDE. Elaboración propia.

3. Del análisis de la distribución geográfica de la AOD bilateral española destinada al sector educativo se desprende que ésta se concentró fundamentalmente en América Latina (que recibió el $60 \%$ de los fondos), África Subsahariana (el 13\%) y el Norte de África (el 12\%). Aunque el número total de países que recibieron ayuda española para el sector educativo fue elevado (más de 100 países), el grado de concentración también lo es, puesto que sólo 7 de esos países (Marruecos, Colombia, Perú, Venezuela, Bolivia, Ecuador y Guinea Ecuatorial) concentraron el $35 \%$ de la ayuda. La mayoría de los países receptores son países de niveles de renta media, Índice de Desarrollo Humano (IDH) medio o alto, y un nivel aceptable en cuanto al Índice de Desarrollo Educativo (IDE). Apenas un $2 \%$ de la AOD concedida al sector se destinó a países con valores reducidos en los citados índices de desarrollo.

4. Con respecto al origen de los fondos, algo más del $70 \%$ de la ayuda destinada al sector educativo en el período 1999-2004 provino de organismos 
dependientes de la Administración Central (véase la tabla 2). No obstante, mientras la cuantía de fondos aportada por la AOD descentralizada se mantuvo en los últimos años estabilizada en torno a los 35 millones de euros, la AOD centralizada en el último trienio descendió drásticamente, reduciéndose casi a la mitad.

\section{TABLA 2}

Origen de las contribuciones bilaterales destinadas al sector educativo en el período 1999-2004 (millones de euros)

\begin{tabular}{|l|r|r|r|r|r|r|}
\hline Origen fondos & $\mathbf{1 9 9 9}$ & $\mathbf{2 0 0 0}$ & $\mathbf{2 0 0 1}$ & $\mathbf{2 0 0 2}$ & $\mathbf{2 0 0 3}$ & $\mathbf{2 0 0 4}$ \\
\hline AOD centralizada & 57,6 & 79,8 & 123,4 & 124,2 & 101,6 & 65,3 \\
\hline AOD descentralizada & 16,6 & 76,6 & 32,0 & 34,9 & 36,6 & 34,8 \\
\hline
\end{tabular}

FUENTE: Listado de proyectos 1999 a 2003 y listado provisional de proyectos 2004, DGPOLDE. Elaboración propia.

Por orden de importancia cuantitativa, las entidades que aportaron recursos a la AOD bilateral en educación en el período de análisis fueron:

- El Ministerio de Asuntos Exteriores aportó el 43\% del total de fondos (335,7 millones de euros). Más de la mitad de estos flujos se destinaron al sector Educación postsecundaria.

- Las Comunidades Autónomas (CCAA) aportaron el 15,5\% de los fondos (130,4 millones de euros). Más de la mitad de dichos fondos los aportaron cuatro comunidades: Gobierno Vasco, Generalitat Valenciana, Comunidad Foral de Navarra y Generalitat de Cataluña. Se da la circunstancia de que en ninguna de éstas el sector Educación básica es prioritario. En cambio, este sector es prioritario para el resto de Comunidades Autónomas, salvo Andalucía, Aragón, Castilla-León y Murcia.

- El Ministerio de Economía, que es el organismo encargado de gestionar la ayuda reembolsable (fundamentalmente, créditos FAD), aportó el $13,2 \%$ de los recursos (103 millones de euros). ${ }^{11}$

11 Tras la reorganización experimentada por la Administración General del Estado en 2004, las competencias en materia de gestión de los créditos FAD fueron traspasadas a la Subdirección General de Fomento Financiero de la Internacionalización, perteneciente al Ministerio de Industria, Turismo y Comercio. 
- Las Entidades Locales (EELL), con el 13\% de la AOD en educación (101,2 millones de euros), centraron su intervención en la inversión en infraestructuras.

- El Ministerio de Educación que aporta el 11,3\% de los fondos (88,7 millones de euros), es el principal origen de los fondos destinados al subsector Servicios e instalaciones educativos, dedicando estos recursos al mantenimiento de los colegios españoles en el exterior.

De todas estas entidades, como se observa en el gráfico 2, el Ministerio de Asuntos Exteriores y las CCAA son los organismos que mantuvieron mayor estabilidad y constancia en su aportación al sector educativo, el resto de entidades participaron de forma más irregular a lo largo del período.

\section{GRÁFICO 2 \\ Evolución de la aportación de fondos a la AOD bilateral española en educación por entidades}

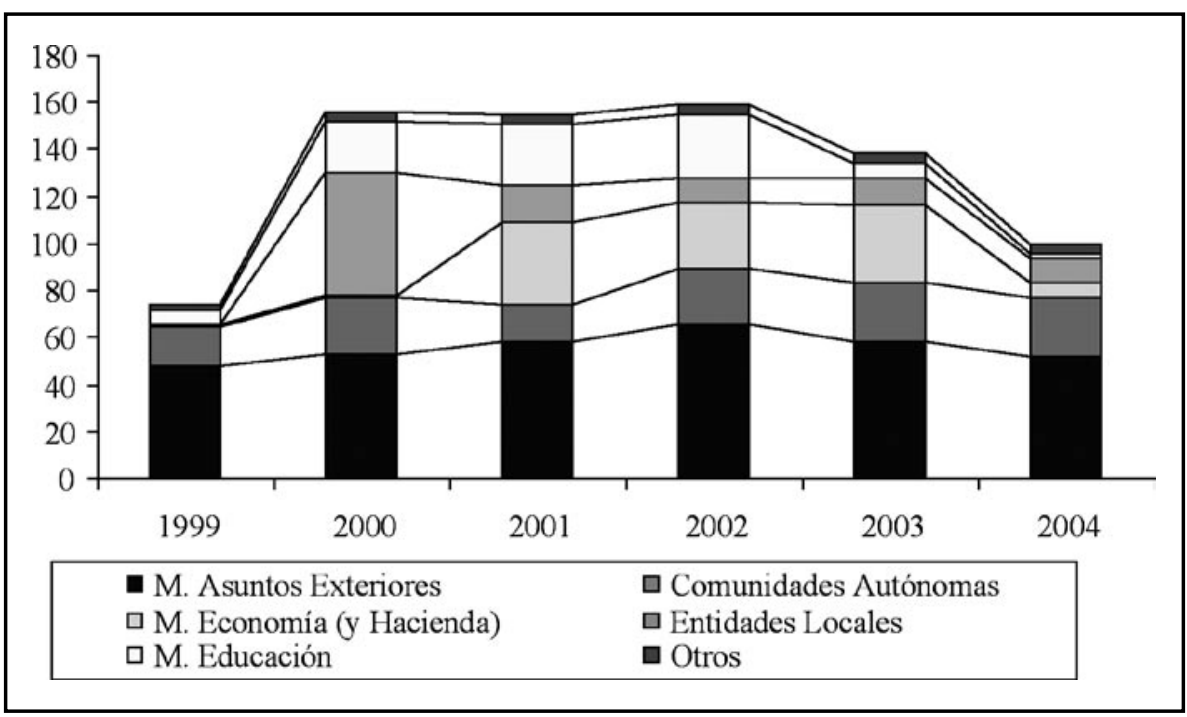

NOTA: Bajo la denominación "Otros" se encuentran agrupados los Ministerios de Trabajo y Asuntos Sociales, Fomento, Interior, Medio Ambiente, Administraciones Públicas, Ciencia y Tecnología y también las universidades y otras entidades públicas.

FUENTE: Listado de proyectos 1999 a 2003 y listado provisional de proyectos 2004, DGPOLDE. Elaboración propia. 
5. En cuanto a su ejecución: algo más del 38\% de la AOD destinada a educación fue canalizada a través de ONGD (301 millones de euros). Estas organizaciones canalizaron el $90 \%$ de los fondos que las CCAA y EELL destinaron al sector educativo y solamente el $16 \%$ de lo aportado por la cooperación centralizada. La mitad de los fondos canalizados por la vía de las ONGD se destinaron al sector Educación, nivel no especificado, casi un 25\% al sector Educación básica, un $22 \%$ a Educación secundaria y sólo un 3,3\% a Educación postsecundaria. El nuevo sistema de financiación a las ONGD aplicado a partir del año 2001 contribuyó a una elevada concentración de los fondos provenientes de la Administración Central entre dichas entidades (5 ONGD concentraron el 50\% de estas subvenciones y 16 el $80 \%$ ). Entre ellas, coexisten ONGD claramente especializadas en educación, con otras que, aunque destacan por la cuantía de recursos destinados a proyectos de educación, también destinaron cuantías similares de AOD a otros sectores. Sin embargo, en el caso de las ONGD que intervinieron en la ejecución de proyectos de educación financiados con fondos de la AOD descentralizada existe una elevada dispersión (el número de entidades que participaron fue mucho mayor que en el caso de la AOD centralizada, y los montantes de los proyectos que ejecutaron fueron de menor dimensión económica).

6. En relación a la distribución sectorial de la AOD en educación (véase la tabla 3), en el período 1999-2004 podemos afirmar lo siguiente:

- La mayor parte de los fondos (el 66\% del total) se concentraron en los sectores Educación, nivel no especificado y Educación postsecundaria.

- Al sector Educación, nivel no especificado, se destinaron casi 263 millones de euros (el 33,5\% de la AOD del sector educativo en el período considerado). La enorme cantidad de fondos destinada a este sector, sobre todo en 2000 (casi se sextuplicó la cuantía de fondos con respecto a 1999) y en 2001, se explica por el incremento de proyectos destinados a la reconstrucción de infraestructuras tras el desastre causado en Centroamérica por el huracán Mitch. En los años posteriores, los fondos destinados a este sector fueron disminuyendo hasta el año 2003, aunque de nuevo aumentaron en el año 2004. 


\section{TABLA 3. Distribución por sectores CAD/CRS de la AOD bilateral bruta en educación 1999-2004}

\begin{tabular}{|c|c|c|c|c|}
\hline $\begin{array}{l}\text { Código } \\
\text { CAD }\end{array}$ & $\begin{array}{l}\text { Código } \\
\text { CRS }\end{array}$ & DESCRIPCIÓN SECTOR & Importe euros & $\begin{array}{c}\text { \% sobre } \\
\text { AOD } \\
\text { educación }\end{array}$ \\
\hline \multirow[t]{5}{*}{111} & & $\begin{array}{l}\text { Educación, nivel no } \\
\text { especificado }\end{array}$ & $262.870 .897,69$ & $\mathbf{3 3 , 5 5}$ \\
\hline & 11110 & $\begin{array}{l}\text { Política educativa y gestión } \\
\text { administrativa }\end{array}$ & $83.869 .610,75$ & 10,71 \\
\hline & 11120 & $\begin{array}{l}\text { Servicios e instalaciones } \\
\text { educativas y formación }\end{array}$ & $156.090 .791,21$ & 19,92 \\
\hline & 11130 & Formación de profesores & 21.198.546,97 & 2,71 \\
\hline & 11181 & Investigación educativa & $1.711 .948,76$ & 0,22 \\
\hline \multirow[t]{4}{*}{112} & & Educación básica & 118.693.113,23 & 15,15 \\
\hline & 11220 & Educación primaria & $65.500 .468,70$ & 8,36 \\
\hline & 11230 & $\begin{array}{l}\text { Capacitación básica de } \\
\text { jóvenes y adultos }\end{array}$ & $46.029 .788,70$ & 5,88 \\
\hline & 11240 & Educación primera infancia & 7.162.855,83 & 0,91 \\
\hline \multirow[t]{3}{*}{113} & & Educación secundaria & $149.402 .243,01$ & 19,07 \\
\hline & 11320 & Educación secundaria & $15.442 .601,26$ & 1,97 \\
\hline & 11330 & Formación profesional & 133.959.641,75 & 17,10 \\
\hline \multirow[t]{4}{*}{114} & & Educación postsecundaria & 252.463.978,30 & 32,23 \\
\hline & 11420 & Educación universitaria & $227.668 .933,96$ & 29,06 \\
\hline & 11430 & $\begin{array}{l}\text { Formación superior técnica } \\
\text { y de dirección }\end{array}$ & $24.795 .044,34$ & 3,16 \\
\hline & & TOTAL AOD EDUCACIÓN & 783.430.232,23 & 100,00 \\
\hline
\end{tabular}

FUENTE: Listado de proyectos 1999 a 2003 y listado provisional de proyectos 2004, DGPOLDE. Elaboración propia.

- El sector Educación básica recibió 118 millones de euros, lo que supuso el $15,1 \%$ de la AOD en educación y tan sólo el 1,7\% del total de la AOD bilateral bruta.

Dentro de este sector, al subsector Educación primera infancia se destinaron unos 7 millones de euros, lo que supuso solamente el $0,9 \%$ de la AOD en educación. Es el subsector que menos fondos recibe de la AOD española (después del subsector Investigación educativa). El 60\% de los recursos fueron aportados por la cooperación descentralizada. La cooperación centralizada 
fue disminuyendo los flujos de fondos destinados a este subsector hasta el año 2003, apreciándose, sin embargo, un significativo incremento en el año 2004. Más de tres cuartas partes de los fondos totales se destinaron a la inversión en infraestructuras y mantenimiento de las intervenciones en este subsector. Colombia, El Salvador, Marruecos y Guatemala fueron los principales receptores de los fondos destinados a este subsector en el período contemplado.

Al subsector Educación primaria se destinaron 65,5 millones de euros (el $8,4 \%$ de la AOD en educación). A pesar del enorme ritmo de crecimiento que fue experimentando la cuantía de fondos destinada a este subsector, hasta llegar en 2003 a una cuantía igual a cinco veces la de 1999, se produjo una considerable reducción en el año 2004, por lo tanto, si parecía que la orientación hacia la educación primaria estaba ganando fuerza en los últimos años, tal y como requiere el cumplimiento de los objetivos adoptados en el Foro Mundial sobre la Educación celebrado en Dakar en el año 2000, parece que se da un paso atrás en el año 2004. La AOD descentralizada financió el 58\% de los fondos destinados a Educación primaria durante los años de estudio. El 5\% de la AOD destinada a primaria se concedió a países con tasas netas de matriculación inferiores al $40 \%$, el $7 \%$ a países con tasas entre el 41 y el $70 \%$ y más del $82 \%$ a países con tasas de matriculación superiores al $70 \%$. El $18 \%$ de la AOD se destinó a países en los que el porcentaje de alumnos que terminan el $5^{\circ}$ grado es inferior al $60 \%$.

El subsector Capacitación básica de jóvenes y adultos recibió un total de 46 millones de euros (casi el 6\% de la AOD educación). La mayor parte de los fondos (el 66\%) fueron aportados por la cooperación centralizada, principalmente a través de los Programas de Alfabetización y Educación Básica de Adultos (PAEBA), llevados a cabo en países latinoamericanos, que se han centrado fundamentalmente en alfabetización. Un porcentaje reducido de la AOD dedicada a este subsector se destinó a países con tasas de alfabetización inferiores al 50\% (generalmente africanos).

- El sector Educación secundaria recibió un total de 149 millones de euros (el 19\% de la AOD educación).

Dentro de este sector, a Educación secundaria apenas se han destinado 15 millones de euros (el $2 \%$ de la AOD educación), de los cuales un 70\%, aproximadamente, es aportado por la cooperación centralizada. La intervención en 
secundaria de la AOD centralizada, se ha concentrado en tres actuaciones cuestionables: mantenimiento de colegios españoles en el exterior, crédito FAD a Panamá concedido en 2001 y reconstrucción de una escuela en Irak.

Al subsector formación profesional se han destinado 134 millones de euros, lo que supone el $90 \%$ de los fondos destinados al sector de educación secundaria y el 17\% de la AOD en educación. También en este subsector dos tercios de los fondos totales provienen de la AOD centralizada, la mitad de la cual aproximadamente es reembolsable. Entre la AOD centralizada no reembolsable destaca el Programa de las Escuelas Taller que absorbe en este período 24,6 millones de euros. Los créditos FAD, que se comienzan a conceder a partir de 2001, son dedicados a la construcción de infraestructura.

- Al sector Educación postsecundaria se destinaron en el período de análisis 252 millones de euros (el 32\% de la AOD educación).

Dentro de este sector, el que más fondos concentra es el subsector de educación universitaria (29\%), casi la totalidad de dichos fondos fueron aportados por la cooperación centralizada. La cooperación española dedicó a educación universitaria el doble de fondos que a Educación básica. Si hacemos la comparación por subsectores, la cooperación española destinó a educación universitaria 30 veces más recursos que a educación infantil, 3,5 veces más que a educación primaria, 5 veces más que a capacitación básica de jóvenes y adultos y 15 veces más que al subsector educación secundaria. Teniendo en cuenta que el acceso a la etapa de educación superior en los países en desarrollo es muy minoritario y elitista, nos parece excesiva la cantidad de fondos que se destina a esta etapa educativa, en detrimento de las demás etapas.

En esta misma línea destacamos que la cooperación española destina a la formación superior técnica y de dirección casi 25 millones de euros. De éstos el $85 \%$ proviene de la Administración Central, importe que equivale a las tres cuartas partes de lo que la AOD centralizada dedica a educación primaria y dos veces más de lo que dedica al subsector educación secundaria.

Como conclusión general sobre la tendencia y distribución de la cooperación española entre los distintos subsectores educativos pensamos que ésta responde, más que a una estrategia definida sobre los sectores hacia los que se deben dirigir los mayores esfuerzos, a una definición determinada por la demanda de los actores que intervienen. Así, en el caso de la coopera- 
ción centralizada los esfuerzos se dirigen hacia los niveles superiores, por la intervención de las universidades, empresas y, en menor medida, ONGD, y en el caso de la descentralizada hacia las etapas inferiores por la demanda de las ONGD.

7. Con respecto a los instrumentos utilizados por la AOD bilateral española para educación cabe destacar el papel de los créditos $\boldsymbol{F A D}$. La AOD concedida con carácter reembolsable para educación se materializó en 42 proyectos cuya cuantía supuso, aproximadamente, el 18\% del total de la AOD en educación si consideramos el período $2001-2004^{12}$, convirtiéndose en uno de los principales instrumentos empleados por la AOD bilateral española en este sector durante los últimos años del período analizado. Consideramos que estamos ante un instrumento de importancia cuantitativa considerable en la AOD educativa española, pero, sin embargo, dudamos de su orientación hacia la educación como sector estratégico para la lucha contra la pobreza. Aunque mantuvo una tendencia creciente durante los años 2001-2003, en el año 2004 disminuyó la cuantía de los créditos FAD, aunque no podemos afirmar que ello sea indicio de un cambio de tendencia en el uso de este instrumento.

Los receptores de ayuda reembolsable fueron principalmente países de nivel de renta $3^{13}$ (48\%) y 4 (33\%), aunque también recibieron este tipo de ayuda países con nivel de renta 2 (19\%). Entre los países receptores de esta ayuda destacan: Jordania, Venezuela, Ecuador, (los cuales concentran el 55\%), China (8\%), Malasia (7,5\%), Panamá (5\%) y Nicaragua (4,5\%). Para estos países, excepto Nicaragua y Ecuador, los FAD supusieron más del $90 \%$ de la AOD recibida para educación. Los subsectores Servicios e instalaciones educativos y formación, Formación profesional y Educación universitaria, son los que concentran la ayuda reembolsable, que, al ser un instrumento de ayuda ligada (vinculada a la compra de bienes y servicios en España),

12 En los años 1999 y 2000 los listados de proyectos de la DGPOLDE no recogen ningún proyecto en educación con carácter de AOD reembolsable.

13 El CAD clasifica, a efectos estadísticos, a los países receptores de AOD en cinco grupos, según su nivel de renta per cápita. Los de nivel de renta 1 son los países menos desarrollados y los de nivel de renta 5 los que tienen ingresos más altos. Desde el año 2005 el número de grupos se ha reducido a cuatro. Las listas de países que el CAD ha ido publicando a lo largo de los últimos años pueden consultarse en la dirección: http://www.oecd.org/findDocument/ 0,2350,en_2649_33721_1_119669_1_1_1,00.html 
se concreta en suministros y equipos para colegios, centros de formación profesional, universidades y laboratorios.

8. En relación a los objetivos y compromisos internacionales en el ámbito educativo, la cooperación española, hasta el momento, está lejos de alcanzarlos:

- En primer lugar, no se está cumpliendo el compromiso adquirido en la Conferencia Internacional de Financiación para el Desarrollo (celebrada en Monterrey en 2002), consistente en incrementar la AOD total hasta alcanzar una cifra equivalente al 0,33 por ciento del PNB en el año 2006. En el año 2004, a pesar del incremento que experimentó la AOD total, apenas supuso el 0,24\% del PNB. Aunque el nuevo Plan Director 2005-08 tiene como horizonte alcanzar el objetivo aludido, el esfuerzo tendrá que ser sustancial.

- Por otra parte, la cuantía que la cooperación española dedica a la educación en general, y a la educación básica, en particular, está muy por debajo del nivel marcado por las recomendaciones adoptadas en diversos foros y cumbres internacionales encaminadas al cumplimiento de los Objetivos de Dakar.

\section{TABLA 4}

Porcentaje de la AOD bilateral neta destinada al sector educativo y a educación básica en el período 1999-2004 (cifras absolutas en millones de euros)

\begin{tabular}{|l|r|r|r|r|r|r|}
\hline CONCEPTO & \multicolumn{1}{c|}{$\mathbf{1 9 9 9}$} & \multicolumn{1}{c|}{$\mathbf{2 0 0 0}$} & \multicolumn{1}{c|}{$\mathbf{2 0 0 1}$} & \multicolumn{1}{c|}{$\mathbf{2 0 0 2}$} & \multicolumn{1}{c|}{$\mathbf{2 0 0 3}$} & \multicolumn{1}{c|}{$\mathbf{2 0 0 4}$} \\
\hline AOD bilateral neta & 778,46 & 803,89 & $1.249,07$ & $1.059,19$ & $1.019,10$ & $1.101,08$ \\
\hline AOD educación & 74,15 & 156,44 & 155,43 & 159,12 & 138,15 & 100,14 \\
\hline $\begin{array}{l}\text { AOD educación } \\
\text { básica }\end{array}$ & 13,64 & 11,65 & 17,81 & 26,93 & 26,03 & 22,63 \\
\hline $\begin{array}{l}\text { \% AOD educación/ } \\
\text { AOD bil. neta }\end{array}$ & 9,5 & 19,5 & 12,4 & 15,0 & 13,6 & 9,1 \\
\hline $\begin{array}{l}\text { \% AOD educación } \\
\text { básica/AOD bil. neta }\end{array}$ & 1,8 & 1,4 & 1,4 & 2,5 & 2,6 & 2,1 \\
\hline
\end{tabular}

FUENTE: Listado de proyectos 1999 a 2003 y listado provisional de proyectos 2004, DGPOLDE. Elaboración propia. 
Estas recomendaciones quedaron recogidas en la Proposición no de Ley aprobada por la Comisión de Cooperación Internacional para el Desarrollo del Congreso de los Diputados en su sesión de 29 de septiembre de $1999^{14}$ en la que se instaba al Gobierno a destinar el $25 \%$ y el $8 \%$ de la AOD bilateral a educación y educación básica, respectivamente. Como se puede comprobar viendo las cifras recogidas en la tabla 4 , los objetivos señalados están muy lejos de cumplirse.

\section{Recomendaciones}

Tras el análisis de la AOD bilateral española concedida para educación en el período 1999-2004, creemos conveniente el seguimiento de las siguientes recomendaciones:

4.1. Alineación con los compromisos internacionales: priorización de la educación básica de calidad para todos en función de necesidades regionales y estrategias nacionales internas

- La AOD española en educación debe destinarse prioritariamente a garantizar el derecho a una educación básica, gratuita, obligatoria y de calidad para todos, orientando así sus aportaciones hacia el logro de los objetivos que se ha fijado la comunidad internacional en materia de educación y desarrollo. Cuando hablamos aquí de educación básica no lo hacemos en el sentido restrictivo de la clasificación del código CAD (educación infantil, educación primaria y capacitación básica de jóvenes y adultos), sino incluyendo el sector de la educación secundaria (educación secundaria, propiamente dicha, y formación profesional) puesto que estamos convencidas de que dicho sector es fundamental para la consecución de una verdadera educación básica. Recogemos aquí la propuesta realizada por la Coordinadora española de ONGD en su documento $A O D$ y Educación (CONGDE, 2004), según la cual el 70\% de la AOD en educación debería destinarse a los sectores educación básica y educación secundaria.

- Las prioridades sectoriales dentro de la educación básica, entendida en su sentido amplio (en gran medida coincidentes con las establecidas en el Plan Director 2005-08) deberían ser las siguientes:

14 Publicada en el Boletín Oficial de las Cortes Generales (Congreso de los Diputados), Serie D, de 15 de octubre de 1999, Núm, 491, pp. 8-9. 
- La cobertura y carácter educativo del segundo ciclo de la educación infantil (3-6 años) ha de aumentar en cantidad y calidad, sobre todo en zonas como Latinoamérica, donde se pueda garantizar la sostenibilidad, avanzando en la obligatoriedad de este ciclo.

- Es preciso aumentar los esfuerzos para conseguir la universalización de la educación primaria y la mejora de su calidad (reducción de las tasas de repetición, absentismo y abandono, aumento de las tasas de finalización de la etapa y consecución de los aprendizajes básicos).

- La cobertura en secundaria debería aumentar, manteniendo la comprehensividad de la etapa hasta los 14 años (y, si es posible, hasta los 16), favoreciendo los ciclos técnicos al final de la misma para promover una formación reconocida en el mercado laboral.

- La educación y capacitación laboral básica de jóvenes y adultos, ha de ir más allá de la mera alfabetización, en línea con los objetivos asumidos por la comunidad internacional en la V Conferencia Internacional de Educación de Adultos (CONFITEA, Hamburgo, 1997).

- Estando sin cubrir las necesidades educativas básicas de la población en muchos países, la AOD española no debería asignar a la educación universitaria una proporción de los recursos superior a la destinada a las etapas básicas. Además, dado que el acceso a la universidad en los países del Sur es minoritario (la tasa bruta global está en torno al 20\%) y reservado a la población con recursos, es preciso reflexionar y definir con claridad su contribución a la lucha contra la pobreza.

- Es necesario que los esfuerzos que se destinan a inversión en infraestructuras educativas se reorienten hacia actuaciones encaminadas a la mejora de la calidad docente (formación de profesores, investigación educativa). Los proyectos de inversión en infraestructura deben valorar la viabilidad y sostenibilidad del servicio educativo.

\subsection{Contextualización geográfica de la $A O D$}

- La región del África Subsahariana, donde se encuentran los países más pobres y con el IDE más bajo, debería tener un mayor peso relativo en la AOD española en educación y con intervenciones de mayor

\section{RFS}


entidad en menos países, dado que actualmente está excesivamente fragmentada.

- En los países de renta media donde ya se interviene, nos referimos fundamentalmente a Latinoamérica, es conveniente:

- Reorientar la AOD hacia los sectores más vulnerables. El tipo de programas ejecutados nos permite cuestionar si con ellos se cubren las necesidades educativas de las clases populares. Sería necesaria una AOD de carácter más regional, más contextualizada, anclada en los niveles de pobreza de cada país y armonizada con los esfuerzos del resto de donantes.

- Favorecer los eslabonamientos educativos. Es necesario reforzar los sistemas educativos para mejorar la calidad y favorecer el eslabonamiento progresivo de las distintas etapas educativas, empezando por las subetapas de la educación básica y con un horizonte amplio que contemple la educación para todos a lo largo de toda la vida.

- Contextualizar la AOD atendiendo al país concreto de que se trate es también vital para determinar los instrumentos y los actores más adecuados. La universalización de la educación básica convendría alcanzarla mediante sistemas públicos en los países capaces de garantizar el derecho a una educación básica de calidad a todos sus ciudadanos. Por ello debe apoyarse el fortalecimiento de los sistemas públicos educativos en los países en desarrollo cuando éstos estén comprometidos con la Educación Para Todos (EPT). Así, por ejemplo, en aquellos países con planes educativos en el marco de una estrategia más amplia de reducción de la pobreza, la AOD española en educación debe priorizar el apoyo a dichos planes mediante la AOD bilateral (apoyo presupuestario o enfoque sectorial) o multilateral (FTI).

\subsection{Aumento de los recursos precisos para el cumplimiento de los compromisos asumidos}

Como se ha indicado anteriormente, la cooperación española ha asumido los siguientes compromisos: por un lado, elevar al 0,5\% del PNB la cuantía de la AOD neta total, y por otro, destinar el $25 \%$ y el $8 \%$, como mínimo, de la AOD bilateral neta a educación y a educación básica, respectivamente. Para cumplir estos compromisos sería preciso que en el conjunto del período 2005-2008: 
- La AOD destinada al sector educativo alcanzara la cifra de 2.147,72 millones de euros. Esto significaría multiplicar por 3,5 la cuantía de la ayuda correspondiente al período 1999-2004.

- La AOD destinada a Educación básica debe ascender a 687 millones de euros. Esto supondría destinar a este sector prácticamente la misma cantidad de recursos que en 1999-2004 se ha destinado a todo el sector educativo.

\subsection{Actores al servicio de la Educación Para Todos}

- La AOD descentralizada debe mantener su apoyo a la educación básica ampliando el número de actores e instrumentos utilizados. No debería limitar sus actuaciones a proyectos de ONGD; sería deseable que en un horizonte a medio plazo la cooperación descentralizada apoyase las políticas públicas educativas de los países receptores, participando, junto con la centralizada, en nuevos instrumentos como la FTI y el apoyo bilateral sectorial.

- El Ministerio de Asuntos Exteriores debe realmente coordinar la acción en cooperación educativa, como así se contempla en la Ley de Cooperación Internacional al Desarrollo española, y reorientar sus recursos hacia los sectores educativos considerados como prioritarios. Debe abrir espacios de participación a las Comunidades Autónomas y Entes Locales en el diseño y ejecución de los nuevos instrumentos de cooperación.

- El Ministerio deEducación debe incrementar su actuación en los niveles educativos inferiores, donde actualmente es inexistente. En aquellos países donde está garantizada la cobertura de la educación básica su cooperación podría ir encaminada a reforzar los sistemas educativos públicos.

- El Ministerio de Economía debe circunscribir la concesión de créditos FAD a países pobres con dificultad de acceso a créditos en condiciones normales de mercado pero sin problemas de deuda externa. Los créditos FAD deben estar limitados a los niveles educativos superiores, evitando así actuaciones que debiliten el papel de los estados como garantes del derecho a la educación. Debe actuar siempre en un marco de complementariedad y coordinación con el resto de los agentes educativos. 
- Las Comunidades Autónomas y Administraciones Locales deben definir y/o mejorar sus políticas de cooperación al desarrollo y reorientarlas hacia la EPT. Sus intervenciones deben realizarse en coordinación con el resto de los agentes y contextualizadas geográficamente. Deben incorporar nuevos instrumentos de financiación, como el apoyo presupuestario, a su política de cooperación directa.

- Las ONGD deben buscar en sus intervenciones la complementariedad y no la sustitución del estado receptor. En los contextos donde la política y acción educativa estatal sea débil sus acciones deben ser subsidiarias y encaminadas al fortalecimiento de los sistemas educativos.

- Las universidades españolas deben contribuir realmente al fortalecimiento de la educación superior y de las universidades de los países en desarrollo, en función de las necesidades particulares de cada país beneficiario y no de sus propios intereses. La cooperación realizada por nuestras universidades no puede limitarse a meros intercambios de alumnado o movilidades del profesorado, como tampoco pretender ocupar el espacio de las ONGD.

La universidad puede y debe jugar también un papel fundamental en la educación para el desarrollo, dando a conocer a nuestros propios ciudadanos la realidad de la pobreza y exclusión del mundo, así como sus causas.

\subsection{Coordinación y complementariedad}

- Los actores son muchos y de diversa naturaleza, todos ellos pueden contribuir al logro de los objetivos la Educación Para Todos. Pero para ello, es necesario que los distintos actores avancen en el diseño y ejecución de actuaciones a través de políticas basadas en la coordinación y complementariedad. El análisis realizado pone de manifiesto la escasa dosis de concertación de los distintos actores. El consenso debe partir de una voluntad de todos los agentes de cooperar y de establecer espacios de diálogo y debate. La ley de cooperación al desarrollo establece en el ámbito nacional el Consejo de Cooperación al Desarrollo, el Consejo Interministerial y el Interterritorial, junto con ellos distintas comunidades autónomas han creado Consejos con similares competencias en el ámbito autonómico e igualmente ocurre en el ámbito local. Sin perder el horizonte establecido por la ley de cooperación, todos estos ámbitos 
son espacios privilegiados de intercambio y diseño de políticas. La participación en ellos es un medio para avanzar en la coherencia de las políticas educativas.

\subsection{Instrumentos al servicio de la Educación Para Todos}

- Los instrumentos no deben ser un fin en sí mismos sino un medio al servicio de los objetivos de la EPT; no deben, pues, condicionar las políticas y prácticas de la AOD en educación. Es necesario redefinir algunos instrumentos para orientarlos decididamente al desarrollo sostenible de los países beneficiarios, a pesar de la dificultad que pueda suponer contemporizar los intereses de los donantes y de los beneficiarios. Esto afecta sobre todo a los FAD, pero también a los programas de becas y lectorados del Ministerio de Asuntos Exteriores. Hay que tender a una utilización complementaria de los instrumentos en el marco de una estrategia orientada a los objetivos de la EPT en cada país.

- Los programas y proyectos de ONGD deben contextualizarse geográficamente. Es necesario avanzar hacia estrategias sectoriales de intervención en el marco de los Planes País de la cooperación española.

- Las evaluaciones positivas de los PAEBA y las Escuelas Taller recomiendan la continuidad de estos programas y la ampliación hacia otras áreas geográficas.

- Los programas de becas y lectorados deben ser evaluados y reorientados hacia el reforzamiento de los sistemas universitarios y organizativos nacionales.

- Los créditos FAD deben ser evaluados desde la perspectiva de contribución al reforzamiento de los sistemas educativos nacionales. La concesión de un crédito FAD debe ir precedida de una evaluación siguiendo las recomendaciones establecidas en el Plan Director. Los créditos FAD deben convertirse en un instrumento complementario y de bajo peso sobre el conjunto de las intervenciones educativas realizadas por la cooperación española en un país. 


\subsection{Revisión de la Estrategia de Educación de la cooperación española}

- En la actualidad se está procediendo a la revisión de la Estrategia de Educación de la cooperación española, es, por tanto, un momento clave para reorientar la AOD en educación española hacia la consecución de los objetivos de la EPT. Para esto es necesario que tanto actores como instrumentos se pongan al servicio de estos objetivos, el análisis de lo acontecido en los últimos años nos ha llevado a afirmar que esto no ha sido así, es el momento de actuar en la dirección correcta.

- La Estrategia de Educación debe ser reelaborada conjuntamente por los distintos actores españoles (gobiernos central, autonómico y local, universidades, empresas, ONGD y otros agentes sociales). No debe ser una simple suma de esfuerzos individuales sino el resultado de un proceso de coordinación y complementariedad de agentes, tal y como recomienda la Declaración de París ${ }^{15}$ y el propio Plan Director de la Cooperación española (2005-08).

- Debe recoger una apuesta por la cooperación multilateral: coordinación internacional de actores y participación activa en el diseño y ejecución de nuevos instrumentos multilaterales (la FTI)

- La estrategia sectorial de la AOD debería tener en cuenta, simultáneamente, dos criterios generales de actuación:

- Las brechas en educación básica (Índice de Desarrollo Educativo) en cada región y/o país. Esto supondría en el caso de América Latina, contribuir a aumentar la cobertura en educación infantil (ciclo 3-6) y secundaria (incluyendo ciclos formativos técnicos), y a mejorar la calidad de la educación primaria. En el caso de regiones o países con índices de desarrollo humano y educativo bajos -como los de África Subsahariana, entre otros-, los Objetivos del Milenio de universalización de la educación primaria y equidad de género podrían ser el horizonte inmediato de actuación.

- El grado de compromiso de los países receptores con los objetivos de la EPT. El objetivo prioritario es alinear la ayuda con los planes educativos de aquellos países que asuman estos compromisos y no dispongan de suficientes recursos propios para alcanzarlos.

15 Declaración de París sobre la Eficacia de la Ayuda al Desarrollo de 2 de marzo de 2005 con motivo del II Foro a alto nivel sobre la Eficacia de la Ayuda al Desarrollo. 
- En consonancia con estos criterios, serán también principios básicos de referencia:

- El principio de subsidiariedad para el empoderamiento (no sustituir la necesaria y obligatoria responsabilidad de las administraciones educativas de los países por intervenciones de la sociedad civil, sino fortalecer prioritariamente la capacidad de cobertura y la calidad de sus sistemas educativos).

- El principio de complementariedad entre administración pública-sociedad civil (allí donde, pese a lo anterior, el sistema educativo público no pueda satisfacer las necesidades educativas básicas, se debe promover y facilitar actuaciones de las organizaciones educativas sin ánimo de lucro especializadas y comprometidas con los objetivos de la Educación Básica para Todos).

\subsection{Educación para el desarrollo}

La ausencia de información y formación de la sociedad civil sobre la EPT puede favorecer actuaciones de menor compromiso en los actores. Es necesario destinar recursos hacia la Educación para el Desarrollo (EPD) generadoras de un cambio de actitudes y conocimientos de la sociedad española para que ésta demande a la administración pública, ONGD y otros actores de la cooperación acciones en el ámbito educativo desde la óptica de la EPT.

\subsection{Revisión y ajuste del sistema CRS del CAD a los objetivos de la EPT}

Sería necesario una reclasificación de los códigos CAD para incluir también dentro del sector de la Educación Básica la educación secundaria y la educación y capacitación laboral básica de jóvenes y adultos.

\subsection{Sobre la calidad de la información disponible en materia de AOD bilateral española}

Para poder realizar un buen análisis de la AOD española en general, y de la dedicada al sector educativo en particular, es necesario disponer de una base de datos correctamente documentada. Dicha base nos debería permitir no sólo conocer qué se está haciendo y quién lo está haciendo, sino además, evaluar la calidad de nuestra cooperación, y medir el grado de consecución 
de los objetivos y compromisos que en materia de educación se han acordado en los distintos foros internacionales. Si bien se observa una mejora en el registro de la información de los listados de proyectos de los últimos años, en el análisis se han detectado datos perdidos (campos no cumplimentados), errores de registro, incoherencia en la formulación y contenido de algunas variables, así como alteraciones de la estructura de los listados anuales que ha impedido el análisis y seguimiento temporal de alguna de las variables. Todo ello ha dificultado el análisis estadístico y ha supuesto algunas limitaciones a nuestro estudio. Por ello estimamos la necesidad de:

- Instar a los distintos actores que aportan fondos para la AOD, y a las entidades que ejecutan proyectos y programas de cooperación a que faciliten toda la información necesaria para poder tener una imagen fiel de las actuaciones de España en materia de AOD.

- Mayor rigor en el registro de la información. En ocasiones una misma ONGD puede aparecer nombrada de diferente forma en distintos registros, en otras, los nombres no están completos; existen agrupaciones genéricas que impiden conocer la realidad (nos referimos a agrupaciones del tipo "Varios Ayuntamientos", "Varios países de Iberoamérica", etc.); otras veces un mismo proyecto es clasificado en distinto sector CRS según el año de realización.

- Construir y actualizar permanentemente la base de datos considerando las líneas estratégicas de la cooperación española, de manera que nos permita conocer no sólo el conjunto de proyectos que han sido aprobados en un determinado período sino también el grado de consecución de los mismos así como de los objetivos establecidos en materia educativa.

- Añadir variables que permitan la evaluación de las intervenciones de la AOD española en educación (proyectos y programas). Así, por ejemplo, deberían incluirse variables que informaran, con carácter retroactivo, sobre la ejecución de los proyectos previamente aprobados, el grado de ejecución periódica, año de finalización, consecución de objetivos, etc. 


\section{Referencias bibliográficas}

Angulo, G. (2001), De Jomtien a Dakar. Diez años de ayuda a la Educación para Todos, Barcelona: Intermón-Oxfam.

BOCG, Congreso De los Diputados (1999a), "Proposición no de Ley presentada por el Grupo Socialista del Congreso, relativa a que las cantidades asignadas a los sectores sociales básicos, educación básica y educación en general, representen el 20 por ciento, 10 por ciento y 25 por ciento, respectivamente, del total de ayuda bilateral oficial al desarrollo", VI Legislatura, Serie D, 21 de junio de 1999, Núm. 449, pp. 12-14.

BOCG, Congreso de los Diputados (1999b), “Aprobación, con modificaciones, de la Proposición no de Ley presentada por el Grupo Socialista del Congreso, relativa a que las cantidades asignadas a los sectores sociales básicos, educación básica y educación en general, representen el 20 por ciento, 10 por ciento y 25 por ciento, respectivamente, del total de ayuda bilateral oficial al desarrollo, así como enmienda formulada a la misma", VI Legislatura, Serie D, 15 de octubre de 1999, Núm. 491, pp. 8-9.

COORDINADORA DE ONGD (CONGDE) (2001) España ante el examen 2001. Comité de ayuda al desarrollo de la OCDE, mimeografiado.

Inge, K., Conceicao, P., Le Goulven, K. y Mendoza, R. (...), ¿Por qué interesan, hoy en día, los bienes públicos globales?, UNDP (tomado en www.undp.org/globalpublicgoods/globalization/pdfs/spanish1.pdf, abril de 2004)

Ministerio de Asuntos Exteriores, Secretaría de Estado para la CoOperación InTERnacional y para Iberoamérica, Oficina de Planificación y Evaluación (2001), Seguimiento PACI-99, Madrid: Secretaría General de la AECI.

Ministerio de Asuntos Exteriores, Secretaría de Estado para la Cooperación Internacional y para Iberoamérica, Oficina de Planificación y Evaluación (2002), Seguimiento PACI-2000, Madrid: Secretaría General de la AECI.

Ministerio de Asuntos Exteriores, Secretaría de Estado para la Cooperación Internacional y para Iberoamérica, Oficina de Planificación y Evaluación (2003), Seguimiento PACI-2001, Madrid: Secretaría General de la AECI.

Ministerio de Asuntos Exteriores, Secretaría de Estado para la CoOperación InTERnacional y para Iberoamérica, Oficina de Planificación y Evaluación (2004), Seguimiento PACI-2002, Madrid: Secretaría General de la AECI. 
Ministerio de Asuntos Exteriores y de CoOperación, Secretaría de Estado de CoOperación Internacional, Subdirección General de Planificación y Evaluación de Políticas de Desarrollo (2004), Seguimiento PACI-2003, Madrid: Ministerio de Asuntos Exteriores, SA.

Ministerio de Asuntos Exteriores, Secretaría de Estado para la Cooperación InternaCIONAL Y PARA IBEROAMÉRICA (2000), Informe de evaluación 7/2000. El Programa de Cooperación Interuniversitaria en Iberoamérica, Madrid: Ministerio de Asuntos Exteriores.

Ministerio de Asuntos Exteriores, Secretaría de Estado para la Cooperación InternaCIONAL Y PARA IBEROAMÉRICA (2004), Estrategia de la Cooperación Española en Educación, Madrid: Ministerio de Asuntos Exteriores.

Ministerio de Asuntos Exteriores (1998), Evaluación del Programa de Escuelas-Taller en Iberoamérica. Resumen Ejecutivo. http://www.mae.es/NR/rdonlyres/ EA188CFD-3611-466C-B1FF-55B24722644E/0/3EvaEscuelasTaller.pdf

Ministerio de Asuntos Exteriores (2000), Informe de evaluación 9/2000. El Programa de Alfabetización y Educación Básica de Adultos PAEBA. Informe ejecutivo, http://www.maec.es/NR/rdonlyres/BA531E65-51A2-4ECD-B60F268A99493920/0/9EvaPAEBA.pdf

NARAYAN, D. (2000) La voz de los pobres, ¿hay alguien que nos escuche? Banco Mundial, Madrid: Mundi Prensa,.

Ortega, M. L. ET Al (2005), La AOD en educación a examen. Un análisis de la cooperación española: 1999-2004, Madrid: Entreculturas y Alboan

PNUD, Estrategia de Pobreza y Desigualdad, UNDP, accedido en Internet en www.undp.org/rblac/documents/poverty/poverty_strategy.pdf, abril de 2004.

Torres, R. M. (2000), Educación para todos. La tarea pendiente, Madrid: Editorial Popular, S.A.

TORRes, R. M. (2005), Justicia educativa y justicia económica. 12 tesis para el cambio educativo, Madrid: Entreculturas.

UNESCO (2000), Marco de Acción de Dakar. Educación para Todos: Cumplir nuestros compromisos comunes, París: UNESCO. 


\section{Bases de datos}

Se puede acceder a los listados de proyectos de AOD bilateral, de los diferentes años, en la dirección de Internet:

http://www.mae.es/es/MenuPpal/Cooperacion+Internacional/La+AOD+e spañola.+Estadísticas

\section{Anexo metodológico: estructura de la base de datos}

La Base de Datos obtenida tras unificar los listados de proyectos publicados por la Dirección General de Planificación y Evaluación de Políticas para el Desarrollo se compone de las siguientes variables ${ }^{16}$ :

- Código del proyecto: número de 13 cifras que identifica cada proyecto. Los últimos dígitos coinciden con el código de la entidad que aporta los fondos.

- Código de la entidad que aporta los fondos: número de 7 cifras que sirve para identificar la entidad que aporta los fondos para cada proyecto.

- Descripción de la entidad que aporta fondos (entre ellas podemos encontrar la AECI, las distintas comunidades autónomas y ayuntamientos que aportan fondos, universidades, etc $)^{17}$.

- Tipo de ayuda: distingue las categorías de centralizada o descentralizada. Si los fondos han sido aportados por el gobierno central, a través de alguno de sus ministerios o de otro organismo público se considera ayuda centralizada. Si el origen de los fondos proviene de alguna comunidad autónoma o entidad local se considera ayuda descentralizada.

- Título y descripción del proyecto: la descripción aporta mayor información sobre el contenido del proyecto.

- Código CRS de clasificación de la ayuda según el sector de destino en el país receptor. Es un número de 5 cifras que sirve para identificar dentro

16 Algunas de las variables son originales de los listados de proyectos y otras como tipo de ayuda, año y ejecución se han añadido.

17 Si los fondos han sido aportados por el gobierno central, a través de alguno de sus ministerios o de otro organismo público se considera ayuda centralizada. Si el origen de los fondos proviene de alguna comunidad autónoma o entidad local se considera ayuda descentralizada. 
de cada sector del código CAD, en nuestro caso del sector Educación, los distintos "subsectores" que lo constituyen. ${ }^{18}$

- Descripción del Código CRS: descripción del sector al que se refiere cada código numérico.

- País: al que va destinada la AOD.

- Nivel de renta del país receptor ${ }^{19}$. Se utiliza la clasificación del CAD según la cual los receptores de ayuda se dividen en dos grandes grupos. Por una parte están los 150 países y territorios en desarrollo (grupo I) que son los receptores de la AOD donada por los 22 miembros del CAD. Por otra parte, en el grupo II, se encuentran los países en transición; esto es, países que, sin poder considerarse desarrollados, sí gozan de una situación socio-económica suficientemente buena como para que no se les pueda considerar receptores de ayuda al desarrollo. Los flujos destinados a estos países se etiquetan de Ayuda Oficial (AO) pero no de ayuda oficial al desarrollo (AOD) y por lo tanto no se incluyen en nuestro análisis. En el grupo I, el que nos ocupa, se distinguen 5 niveles de renta ${ }^{20}$, según el valor del PNB (Producto Nacional Bruto) per cápita:

- Nivel 1: países menos desarrollados

- Nivel 2: países con bajos ingresos

- Nivel 3: países con ingresos de nivel medio-bajo

- Nivel 4: países con ingresos de nivel medio-alto

- Nivel 5 : países con ingresos altos

- Importe de la AOD concedida: es decir el importe total en euros destinado a cada proyecto.

18 Para mayor información acerca de la clasificación de la ayuda según los códigos CRS pueden dirigirse a la página web de la OCDE (http://www.oecd.org/dataoecd)

19 En la página web de la OCDE (http://www.oecd.org se puede obtener la lista de los países receptores de AOD del CAD para los distintos períodos en los que dicha lista ha sufrido actualizaciones.

20 Los intervalos de PNB per cápita que se utilizan para clasificar a los países por niveles de renta van siendo actualizados cada 3 años. 
- Modo de ayuda: que distingue proyectos de cooperación técnica, proyectos de inversión, de ayuda para programas y otros recursos. Los primeros hacen referencia a proyectos de asesoramiento técnica y de formación de formadores, los segundos a construcción de escuelas principalmente, los terceros a recursos destinados para programas específicos que dirige y gestiona el país receptor y los cuartos son una especie de cajón de sastre, que en el caso de la educación incluye proyectos como por ejemplo alimentación en las escuelas, material, etc.

- ONGD: si el proyecto ha sido ejecutado por una ONGD esta variable indica su nombre.

- Año: año en que se concede la financiación del proyecto.

- Universidad: si el proyecto ha sido ejecutado por una Universidad esta variable indica el nombre de la misma.

- Ejecución: esta variable indica si el proyecto se ha ejecutado directamente por la entidad que aporta los fondos (ejecución directa), o ha sido ejecutado por una ONG o una Universidad (ejecución indirecta).

- Tipo de cooperación: indica si la AOD tiene carácter reembolsable (es decir debe de ser devuelta por el país receptor) o no reembolsable (si la cuantía de la ayuda se da con carácter gratuito, sin generar devolución alguna).

- Objetivo de la ayuda: por último la base de datos incluye una serie de variables para identificar el grado en que objetivos como la asistencia contra la pobreza, la igualdad de género, el medio ambiente, desarrollo y buen gobierno, integración de pueblos indígenas y la lucha contra el narcotráfico han constituido la finalidad de cada proyecto. Existen cuatro categorías para especificar si el proyecto persigue o no, y en caso afirmativo en qué grado, cada uno de los objetivos mencionados. Estas categorías son:

- Principal;

- Significativo;

- No orientado al objetivo;

- No activado (si se desconoce o no se ha especificado la finalidad del proyecto). 